\title{
Changes in intracellular and extracellular amino acids during the predation of the chlorophyte Dunaliella primolecta by the heterotrophic dinoflagellate Oxyrrhis marina and the use of the glutamine/glutamate ratio as an indicator of nutrient status in mixed populations
}

\author{
K. J. Flynn, J. Fielder \\ Biochemistry Research Group, School of Biological Sciences, University College Swansea, Singleton Park, Swansea SA2 8Pp \\ Wales, United Kingdom
}

\begin{abstract}
Concentrations of intracellular and extracellular (free) amino acids (IAA and FAA respectively) were determined during predation of prey-deplete and prey-replete Oxyrrhis marina on dead, $\mathrm{N}$ deplete and N-replete Dunaliella primolecta, and also during the growth of mixed populations of the 2 organisms over 7 d. Cultures were axenic. Dunaliella did not take up any of 20 FAA tested but Oxyrrhis took up (amongst others) methionine, leucine, valine, and alanine. Uptake of FAA by Oxyrrhis could contribute a significant proportion of nitrogen demand. The composition of FAA in media containing mixed populations differed depending on the nutrient status of both organisms but generally those amino acids present were those for which Oxyrrhis did not show an affinity, although levels of, in particular, alanine increased until Oxyrrhis became prey-deplete and then decreased. Glutamate alanine, arginine, glutamine and serine (and taurine in Oxyrrhis) were the major components of IAA but the proportions varied over a wide range depending on the nutrient status of the organisms. The value of the glutamine/glutamate (GLN/GLU) ratio appeared consistent with the incorporation of $\mathrm{NH}_{4}^{+}$by the population, indicating assimilation by Dunaliella of $\mathrm{NH}_{4}^{+}$regenerated by Oxyrrhis which was not detected in the medium. Elevated GLN/GLU was also indicative of prey-replete Oxyrrhis. However, the evelated levels of GLU, and correspondingly low GLN/GLU, in prey-deplete Oxyrrhis and during initial feeding, could mask the GLN/GLU of Dunaliella if the predator biomass was high. Both prey-deplete Oxyrrhis and N-deplete Dunaliella had GLN/GLU of ca 0.1 .
\end{abstract}

\section{INTRODUCTION}

Changes in levels of individual free (i.e. extracellular) amino acids (FAA) are the result of the interaction of processes of release and uptake which in turn will relate to the composition of the intracellular pools of amino acids (IAA) of the organisms. Flynn \& Butler (1986) discuss this interaction, suggesting that release from healthy cells is likely to be an 'overflow' action but that the composition of FAA in natural waters appears to reflect utilization rather than release. That is to say that those FAAs present in situ are likely to be those for which demand is least. Because bacteria are likely to be major consumers of FAA, especially in the artificial environment of containers, in which bacteria thrive, it is desirable to study interaction of components of a food chain under axenic condition. Andersson et al. (1985) described the release of FAA during the feeding of a microflagellate on bacteria but because the bacteria were not dead some portion of the release was probably taken up by the prey (Flynn \& Butler 1986). The study described in this paper made use of axenic organisms and a prey, Dunaliella primolecta, which has a minimal ability to take up and use FAA for growth (Turner 1979).

The second aim of this work was to examine further the suggestion of Flynn et al. (1989) that the ratio of intracellular glutamine/glutamate (GLN/GLU) could 
be of use in assessing the nutrient status of phytoplankton. Values of GLN/GLU below 0.2 indicate $N$-deficiency and above $0.5 \mathrm{~N}$-replete cells. Admiraal et al. (1986) suggested that an examination of IAA could be used as a 'metabolic fingerprint' for nitrogen status in phytoplankton.

\section{MATERIALS AND METHODS}

Cultures of the chlorophyte Dunaliella primolecta Butcher (CCAP 11/34) (hereafter Duniella) and the dinoflagellate Oxyrrhis marina Dujardin (CCAP 1133/ 5) (hereafter Oxyrrhis) were maintained in artifical seawater with a base of $16 \mathrm{~g} \mathrm{l}^{-1}$ Instant Ocean (Aquarium Systems). Rapid cooling of the Instant Ocean after autoclaving $\left(113^{\circ} \mathrm{C}\right.$ for $\left.10 \mathrm{~min}\right)$ was used to prevent formation of precipitates which may absorb FAA (Flynn 1988a). For Expts II and IIb, the medium was filter-sterilized through a $0.2 \mu \mathrm{m}$ Durapore (Millipore) filter specifically to ensure that no precipitate

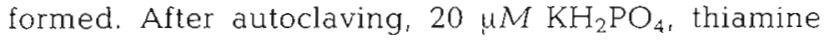
(50 $\left.\mathrm{mg}^{-1}\right)$, and cyanocobalamin $\left(0.5 \mathrm{mg} \mathrm{I}^{-1}\right)$, and $\mathrm{NH}_{4} \mathrm{Cl}$ at the required concentration, were added using a $0.2 \mathrm{um}$ Acrodisc filter (Gelman). All culture vessels were acid-washed and rinsed in double-distilled water and HPLC grade water. Medium was made with HPLC grade water. For all stock cultures other than those used for Expt I, for which $\mathrm{NaNO}_{3}(880 \mu M)$ was used, $\mathrm{NH}_{4} \mathrm{Cl}(100 \mu \mathrm{M})$ was used as $\mathrm{N}$-source. Cultures were maintained at $20^{\circ} \mathrm{C}$ in a $12 \mathrm{~h} / 12 \mathrm{~h} \mathrm{~L} / \mathrm{D}$ cycle $(100 \mathrm{umol}$ $\mathrm{m}^{-2} \mathrm{~s}^{-1}$ ) in static flasks with no aeration.

Methods of sampling, storage of samples, extraction of IAA and analysis of $\alpha$-amino acids and ammonium by HPLC are described in detail by Flynn (1988a). 2Amino $n$-butyric acid (ABA) was used as the internal standard for measurements of FAA but, because ABA was present in the IAA samples, $\alpha$-amino adipic acid (which is not as good as ABA for FAA determinations because of minor contaminants) was used as the internal standard for IAA determinations. Volumes of $3 \mathrm{ml}$ were taken for FAA analysis and cells from 5, 10 or $25 \mathrm{ml}$ collected under $50 \mathrm{~mm} \mathrm{Hg}$ vacuum onto $0.2 \mathrm{fm}$ Acrodisc filters (Gelman) for extraction (freeze-thaw followed by extraction in $2 \mathrm{ml}$ HPLC grade water at $70^{\circ} \mathrm{C}$ for $1 \mathrm{~h}$; Flynn 1988). No obvious leakage of IAA has ever been apparent using this protocol. Cell counts were performed using a haemocytometer or Sedgewick Rafter counting chamber

All chemicals were Analar or HPLC grade. Amino acids are identified by their standard abbreviations (alanine, ALA; arginine, ARG; asparagine, ASN; aspartate, ASP; glutamate, GLU; glutamine, GLN; glycine, GLY; histidine, HIS; isoleucine, ILE; leucine, LEU; lysine, LYS; methionine, MET; ornithine, ORN; phenyl- alanine, PHE; serine, SER; taurine, TAU; threonine, THR; tryptophan, TRP; tyrosine, TYR; valine, VAL)

In order to kill Dunaliella, a $50 \mathrm{ml}$ culture $(100 \mathrm{ml}$ flask j was held at $50^{\circ} \mathrm{C}$ for $10 \mathrm{~min}$. $\mathrm{N}$-deprived cultures were used for this so as to minimize the leakage of amino acids into the medium from dead cells. The principle amino acids which were lost by dead cells were GLU, SER and ALA, which were also the main components of IAA in N-deplete Dunaliella; effectively the entire contents of IAA in dead cells leaked to the medium, Oxyrrhis were starved either by placing the culture in darkness (Expts I and II) so that the Dunaliella were grazed down under C-limiting conditions, or in the normal L/D cycle (Expts III and IV) which is more likely to result in N-limited growth of the prey. For Expts I and II, the Oxyrrhis were harvested asceptically by centrifugation ( $3000 \times g$ for $3 \mathrm{~min}$ ) and resuspended in $\mathrm{N}$-free growth medium before placing the culture in darkness for $3 \mathrm{~d}$.

Essential information for the experiments is presented in Table 1. In addition, for Expt IIb, $10 \mathrm{ml}$ samples were removed from flasks during Expt II into $30 \mathrm{ml}$ sterile transparent polystyrene screw-cap vials every $12 \mathrm{~h}$ (at the beginning of the next light or dark phase) and supplied with a mixture of 20 amino acids (a further $200 \mathrm{n} M$ to that already present from biotic activity), sampled immediately, incubated for $12 \mathrm{~h}$ in the appropriate light conditions and sampled again. This experiment was conducted to test for changes in the ability of the propulation to take up FAA.

In Expt III, $100 \mathrm{ml}$ volumes of prey-deplete Oxyrrhis, and $\mathrm{N}$-deplete and $\mathrm{N}$-replete Dunaliella were supplied with a range of FAA (addition of $200 \mathrm{n} M$ of each amino acid) in order to test for uptake. At intervals, $5 \mathrm{ml}$ volumes were removed and filtered as described above. Samples were also taken to look for any changes in IAA which may occur following uptake.

\section{RESULTS}

\section{Predation and population growth}

Prey-deplete Oxyrrhis were small $1<20 \mu \mathrm{m}$ diameter), with no obvious remains of prey within, and highly motile. Typically, within 1 to $2 \mathrm{~d}$ of feeding, the Oxyrrhis populations comprized large $(50 \mu \mathrm{m}$ diameter $)$, slow-moving cells, containing up to 20 or more Dunaliella. Dunaliella were clearly visible inside Oxyrrhis and a reasonable estimate of prey numbers could be made by microscopic examination. Replete Oxyrrhis also tended to burst on addition $0.5 \%$ Lugol's iodine, releasing prey which then lay just around the Oxyrrhis on the microscope slide where they could be counted. On exhaustion of the prey, the predator population 
Table 1. Experimental conditions. All experiments conducted in $12 / 12 \mathrm{~h}$ light-dark cycle at 18 to $20^{\circ} \mathrm{C}$. Abbreviations: d, dead; Prp/Pdp, prey replete/deplete; Nrp/Ndp, nitrogen replete/deplete. Sample time as hours into light (L) or dark (D) phase

\begin{tabular}{|c|c|c|c|c|c|c|}
\hline \multirow[t]{2}{*}{ Expt } & \multirow[t]{2}{*}{ Fig. } & \multirow[t]{2}{*}{ Flask } & \multicolumn{2}{|c|}{$\begin{array}{l}\text { Initial cell densities } \\
\left(\times 10^{3} \mathrm{ml}^{-1}\right)\end{array}$} & \multirow[t]{2}{*}{$\begin{array}{c}\mathrm{NH}_{4}^{+} \text {addition } \\
\quad(\mu M)\end{array}$} & \multirow[t]{2}{*}{ Sample time } \\
\hline & & & Oxyrrhis & Dunaliella & & \\
\hline \multirow[t]{3}{*}{ I } & 1 & $\mathrm{~A}$ & $0.9 \operatorname{Prp}$ & $48 \mathrm{~d} ; \mathrm{Ndp}$ & 0 & $\mathrm{LO} ; \mathrm{DO}$ \\
\hline & & $\mathrm{B}$ & 0.9 Prp & $48 \quad \mathrm{Ndp}$ & 0 & LO; DO \\
\hline & & C & $0.5 \operatorname{Prp}$ & $87 \quad$ Nrp & 0 & LO: DO \\
\hline \multirow[t]{3}{*}{ II } & 2 & $D$ & $0.3 \mathrm{Pdp}$ & $26 \mathrm{~d} ; \mathrm{Ndp}$ & $0^{a}$ & LO; DO \\
\hline & & $E$ & $0.3 \mathrm{Pdp}$ & $24 \quad \mathrm{Ndp}$ & $0^{a}$ & LO; DO \\
\hline & & $F$ & $0.3 \mathrm{Pdp}$ & $26 \quad$ Nrp & $100^{\mathrm{d}}$ & LO: DO \\
\hline \multirow[t]{3}{*}{ IV } & 6 & $x$ & $0.16 \mathrm{Pdp}$ & Nrp & 50 & L6 6 \\
\hline & & Y & $0.16 \mathrm{Pdp}$ & Nrp & 50 & L6 6 \\
\hline & & $\mathrm{z}$ & $0.16 \mathrm{Pdp}$ & Nrp & 50 & L6 \\
\hline
\end{tabular}

again became dominated by small highly motile individuals. The time scale of this event depended on the initial status of the predator, the nutrient status of the prey, and on the cell density of the prey.

At the start of Expt I (Fig. 1), the Oxyrrhis had not completely removed the prey and the predators contained several ( 3 to 5) Dunaliella. In Expt II (Fig. 2), the predators had been starved of food and remnants of prey were visible within only a few Oxyrrhis. As a consequence, the time by which the Oxyrrhis had become prey-replete (15 to 20 Dunaliella per Oxyrrhis) was $1 \mathrm{~d}$ in Expt 1 but 2d in Expt II. Although levels of $\mathrm{NH}_{4}^{+}$in the medium of Flasks E and F were not limiting growth of the prey, predation was more intense and the population of Dunaliella was rapidly predated. However, there were diurnal fluctuations in prey density in both $\mathrm{E}$ and $\mathrm{F}$

In Flask A. (Expt I; Fig. 1), to which dead Dunaliella had been added to prey-replete Oxyrrhis, a proportion ( $25 \%$ initially) of the prey was alive. It was notable that the dead prey were removed rapidly, apparently selectively, especially within the first $12 \mathrm{~h}$, whilst the live Dunaliella grew to account for $75 \%$ of the prey by Day 1. It was also noted that the initial rate of capture (guaged by the rate of appearance of prey within the Oxyrrhis) of N-replete prey in $\mathrm{C}$ was slower than of $\mathrm{N}$ deplete prey in $\mathrm{B}$, although prey densities were actually higher in the former.

In Expt IV (Fig. 6), in which different prey densities were supplied to prey-deplete Oxyrhis, there were differences in the rates of predation. In Flask X, Oxyrrhis were not full with prey until Day 3 by which time prey density was $50 \times 10^{3} \mathrm{ml}^{-1}$, similar to the initial prey density in $\mathrm{Y}$ in which Oxyrrhis were quite full $(10+$ Dunaliella per cell) after just $1 \mathrm{~d}$. In $Z$, which initially contained $100 \times 10^{3} \mathrm{ml}^{-1}$ Dunaliella, the predators contained $15+$ prey per cell by this time.

\section{Changes in ammonium and extracellular amino acids}

Levels of $\mathrm{NH}_{4}^{+}$reflected use by Dunaliella and release by Oxyrhis, Levels of $\mathrm{NH}_{4}^{+}$in $\mathrm{C}$ increased more rapidly than in $B$ (Fig. 1), presumably reflecting the lower $\mathrm{C} / \mathrm{N}$ ratio of the prey. However, in most instances, $\mathrm{NH}_{4}^{+}$regeneration appears to have been exceeded by demand.

Fig. 3 shows a comparison between FAA in the medium of Dunaliella and of Oxyrrhis after a period of exponential growth (N-source and prey supply exhausted, respectively). GLU, SER and ALA were major components of FAA for Dunaliella, and SER and GLY for Oxyrrhis. The use of dead Dunaliella, as prey in Flasks A (Expt I; Fig. 1) and D (Expt II; Fig. 2), added an additional 70 to $100 \mathrm{nM}$ GLU, $50 \mathrm{nM}$ ALA and $50 \mathrm{n} M \mathrm{SER}$ to these flasks, values which are consistent with levels of FAA in control flasks of dead Dunaliella at 0 h (not shown).

Levels of FAA were generally low but levels of some increased when the predator was prey-replete, and decreased when they were starved of prey or if the prey was of poor quality (dead or $\mathrm{N}$-deplete). For example, levels of ALA and GLY in Flask E (Fig. 2) first decreased and then, as the Oxyrrhisbecame prey-replete, levels increased. In contrast there was a downward trend in FAA levels throughout the period in D (Fig. 2) which contained dead prey. In $X$ (Fig. 6), where the prey did not become $N$ deplete until Day 5 and predators did not exhaust the prey during the experiment, levels of FAA (especially GLU, ALA \& ARG) gradually increased. In contrast, in Z (Fig. 6) which contained prey-deplete Oxyrrhis at the end of the incubation, there was a weaker upward trend in levels of FAA, with levels of ALA and GLY falling towards the end. The vial used to contain the sample for FAA at 2.5 $\mathrm{d}$ in $\mathrm{B}$ was contaminated and data lost. 

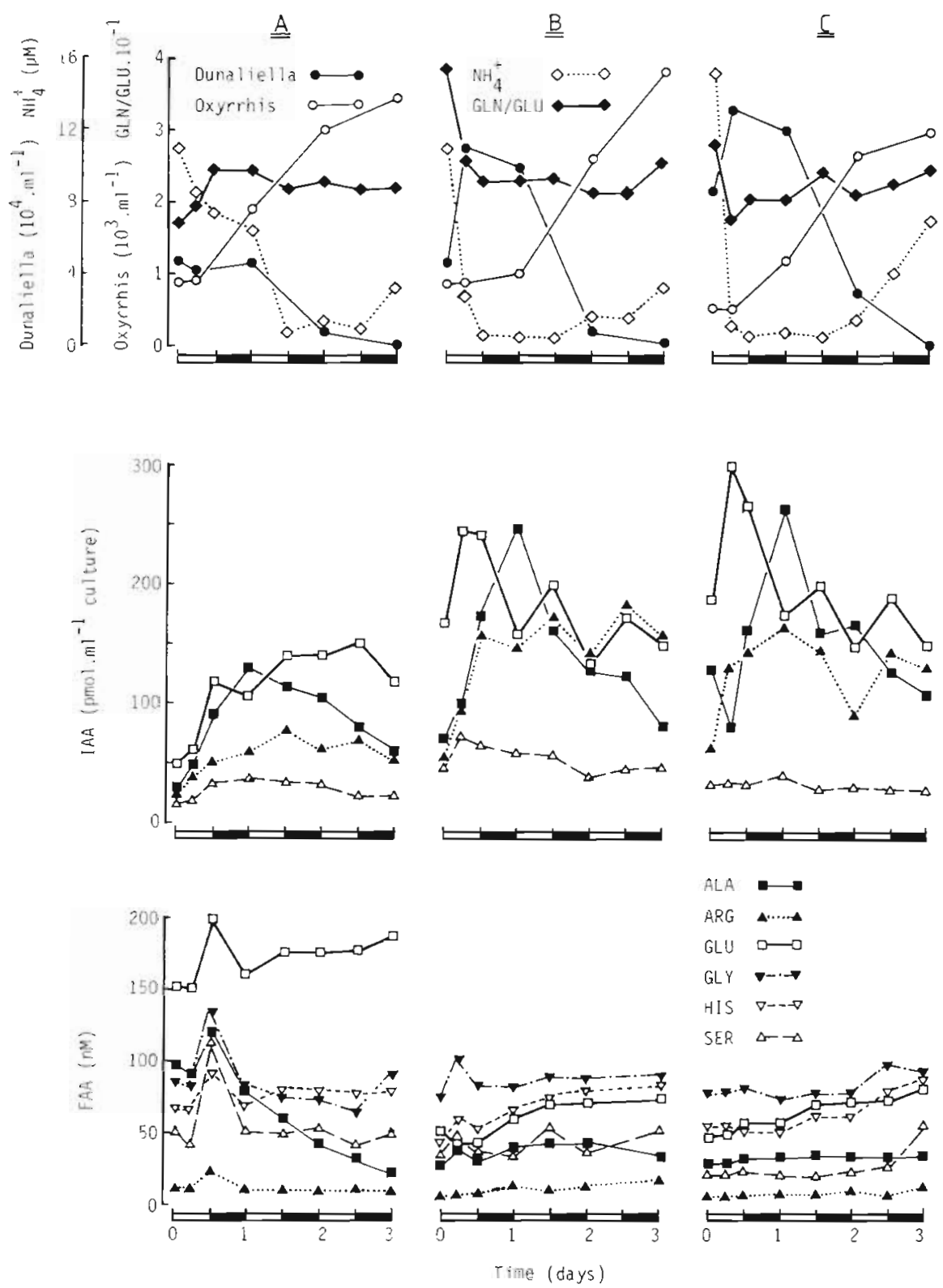

Fig. 1. Expt I. Changes in cell number, $\mathrm{NH}_{4}^{+}$, GLN/GLU, IAA and FAA during predation by prey-replete Oxyrrhis on dead (A), $\mathrm{N}$-deplete (B) and N-replete (C) Dunaliella. Some live prey $(14 \times$ $10^{3} \mathrm{ml}^{-1}$ ) present at Day 0

Note that data are displayed in all figures as moles amino acid, not amino-N, and thus the contribution of amino acids containing more than $1 \mathrm{~N}$ (ARG contains $4 \mathrm{~N}$ ) is greater than it may first appear.

\section{Amino acid uptake}

In Expt IIb (Fig. 4), the general trend for FAA uptake by the population was that uptake was greater in the culture with dead prey (D; Fig. 2) and that uptake rates over the $12 \mathrm{~h}$ incubation increased with increasing Oxyrrhis numbers. This result is consistent with changes in levels of FAA in D and E (Fig. 2). Levels of GLN, MET, VAL, PHE, ILE, LEU and ASP, all of which

were taken up rapidly in this test, were present at low levels in the flasks (Fig. 2). Results for F were similar to those from $E$ (not shown).

Incubations of $\mathrm{N}$-replete and $\mathrm{N}$-deplete Dunaliella with a range of 20 FAA over periods of up to $24 \mathrm{~h}$ showed no significant uptake of any of the test amino acids (data not shown). In contrast, prey-deplete Oxyrrhis did take up FAA (Expt III; Fig. 5a). Some amino acids were taken up more rapidly than others. Only some of those taken up resulted in an increased pool of amino acid within the cells (Fig. 5b). The intracellular pool of MET declined (Fig. 5b) after the MET in the medium was exhausted (Fig. 5a). Note the small size of the pool of these amino acids in comparison with GLU and ARG, for example, D (Fig. 2); cell densities in Expt 
Fig. 2. Expt II. Changes in cell number, $\mathrm{NH}_{4}^{+}$, GLN/GLU, IAA and FAA during predation by prey-deplete Oxyrrhis on dead (D), N-deplete (E) and $N$-replete (F) Dunaliella. Levels of $\mathrm{NH}_{4}^{+}$in $\mathrm{F}$ on average $100 \mu \mathrm{M}$ greater than in $E$ (not shown)
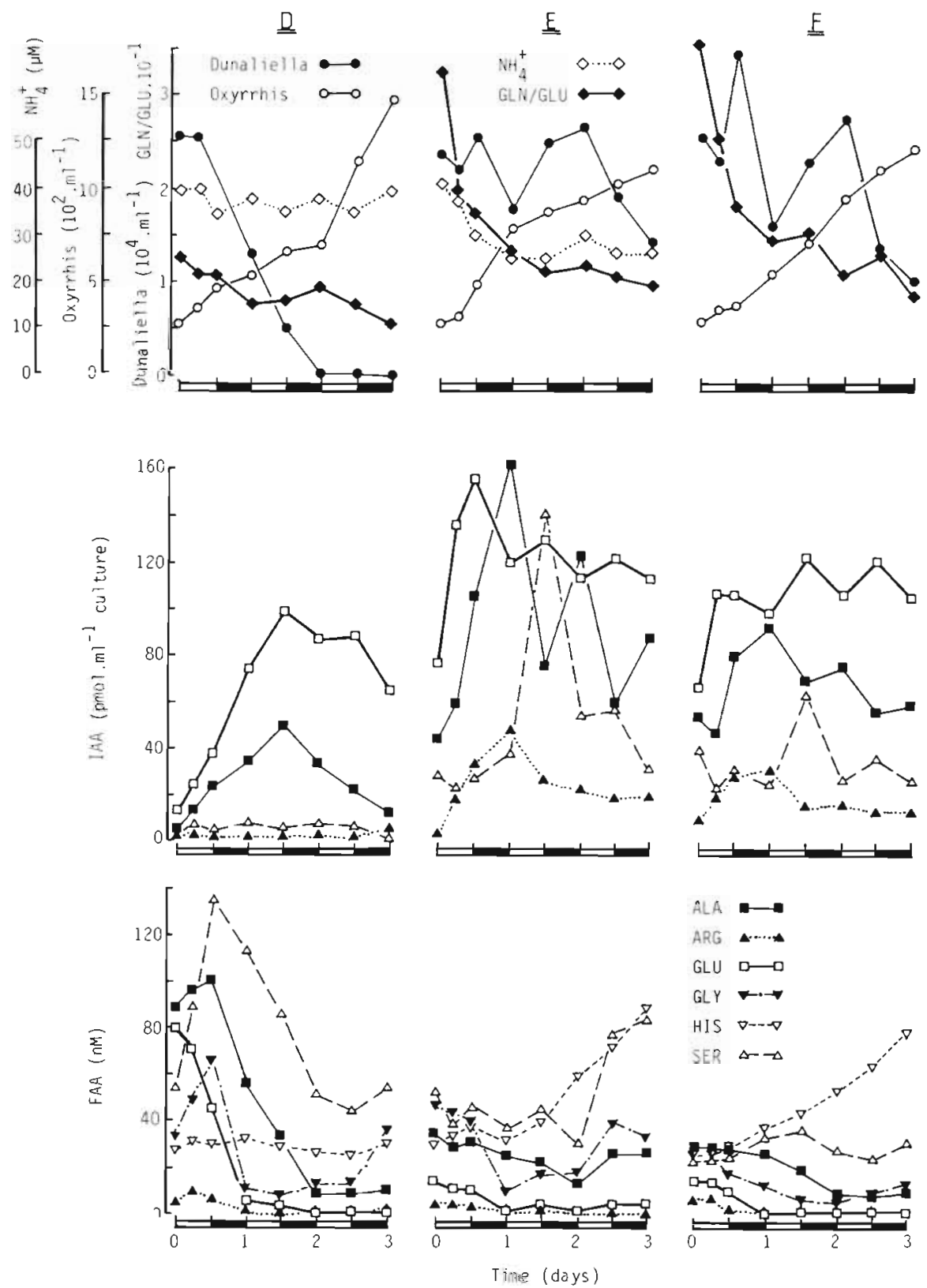

III exceeded those in I and II. At least some of those FAA released by Dunaliella (e.g. ALA, PHE, LEU and THR; Fig. 3) could be taken up by Oxyrrhis and were present at low concentrations in the Oxyrrhis medium. The changes in levels of free ALA and GLY observed in $E$ (Fig. 2) and $Z$ (Fig. 6) were consistent with the ability of prey-deplete Oxyrrhis to take up ALA and GLY.

\section{Changes in intracellular amino acids}

The IAA composition of prey-deplete Oxyrrhis was dominated by HIS $18 \%$, GLU $15 \%$, TAU $15 \%$, ARG $10 \%$, LYS $7 \%$, SER $5 \%$, ALA $4 \%$ (all values as $\%$ of identified amino-N). TAU was present in all extracts of the population and the concentration correlated with that of Oxyrrhis numbers; it was barely detectable in Dunaliella. However, in Oxyrrhis which had been feeding levels of AIA were much higher. By $1.5 \mathrm{~d}$ in D (Expt II; Fig. 2) the dead Dunaliella (whose IAA pool was very low because of leakage) were present at low cell density and the values of IAA for the population essentially represent those of Oxyrrhis. Here values were GLU $28 \%$, LYS $19 \%$, ALA $15 \%$, TAU $7 \%$, ARG $6 \%$, with GLN at $5 \%$.

The IAA composition of N-replete Dunaliella was ARG $40 \%$, GLU $23 \%$, GLN $20 \%$, ALA $12 \%$, LYS $7 \%$, although the composition varied during the L/D cycle. 


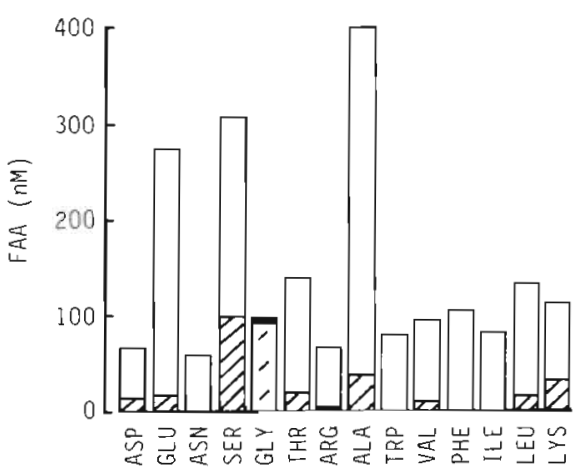

Fig. 3. Concentrations of FAA in the growth medium of Dunaliella (open bars) and Oxyrrhis (shaded bars) after a period of exponential growth. Cell densities: Oxyrrhis $=2.5 \times$ $10^{3} \mathrm{ml}^{-1}$; Dunaliella $=5 \times 10^{6} \mathrm{ml}^{-1}$. (Shaded bars overlay open bars; for GLY, shaded bar is slightly higher than open bar)

During $\mathrm{N}$-deprivation the proportions of GLN and ARG decreased and those of GLU and ALA increased.

There appeared to be a diurnal periodicity in levels of GLU and ALA (Figs. 1 and 2) during predator-prey interaction. There was an increase in GLU and ALA associated with feeding and if the prey were $\mathrm{N}$-replete levels of ARG and SER also increased significantly. The peak for ARG coincided with peak GLN/GLU, suggesting that this component may have been affected most by the N-status of Dunaliella. There was a consistent pattern of the relative timing of peaks of ALA, ARG and SER. Generally the level of ARG peaked before that of
SER with a peak of ALA coinciding with ARG and another ALA peak coinciding with the onset of preydepletion. This is apparent in Figs. 2 and 6.

The pattern of change in GLN/GLU was consistent with growth of Dunaliella (specifically the incorporation of $\mathrm{NH}_{4}^{+}$), although the low GLN/GLU of the predator led to a lower value for the ratio where prey-deplete Oxyrrhis comprised the dominant biomass. In analogy with the changes in GLN/GLU in Dunaliella under differing $\mathrm{N}$-status, the ratio was also low for prey-deplete Oxyrrhis (Fig. 2, Flask D, in which prey-deplete Oxyrrhis were fed with dead Dunaliella whose contribution to IAA was negligible) and higher for prey-replete Oxyrrhis (Fig. 6. Flask Z, in which by Day 6 the dominant biomass was Oxyrrhis). GLN/GLU fell sharply when $\mathrm{NH}_{4}^{+}$was exhausted by Dunaliella (B, Fig. 1; X, Y and Z, Fig. 6) but increased again where the study period allowed time for regeneration and utilization of $\mathrm{NH}_{4}^{+}$ (Expt IV; Fig. 6). There was no significant increase in $\mathrm{NH}_{4}^{+}$during this process suggesting that release and uptake must have been closely coupled.

\section{DISCUSSION}

\section{Pattern of predation}

The method of prey capture by Oxyrrhis, and the subsequent digestion of Dunaliella, has been examined by electron microscopy coupled with an analysis of IAA; results will appear elsewhere (Öpik \& Flynn unpubl.).

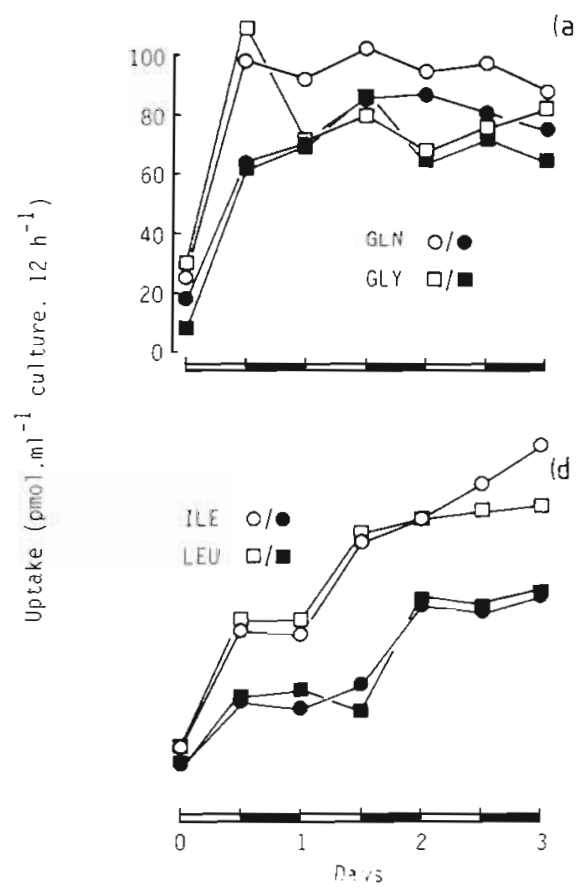

la

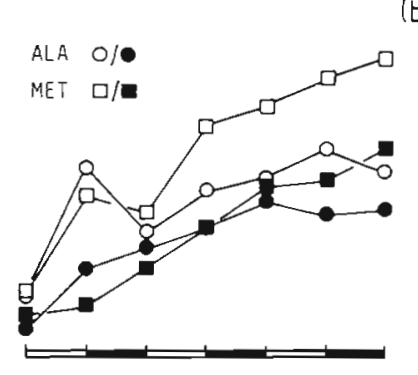

ib

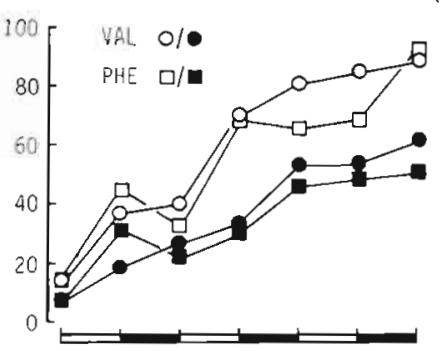

$1 c$

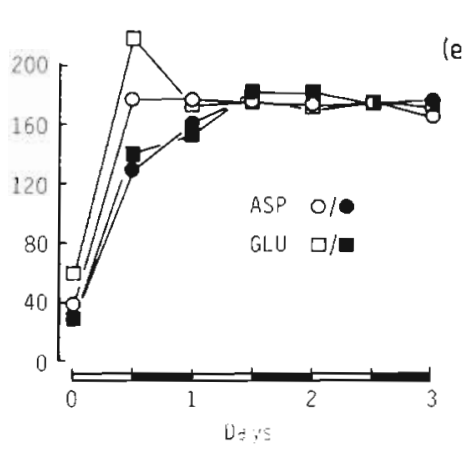

Fig. 4. Expt IIb. Uptake of FAA by predatorprey population of Flasks $D$, dead prey, (open symbols) and E, N-deplete prey. (closed symbols) in Expt II (Fig. 2). Samples were supplied with $200 \mathrm{n} M$ each amino acid. Values are pmoles removed from the medium $\mathrm{ml}^{-1}$ over $12 \mathrm{~h}$ 
Although a specific set of experiments was not designed to investigate rates of capture, from our microscope observations of the appearance of prey within Oxyrrhis, the rate of capture appeared to be dead prey quickest, then $\mathrm{N}$-deplete prey and then $\mathrm{N}$-replete prey. During microscopy of live organisms, the 2 organisms appeared in clusters more frequently when the Dunaliella were $\mathrm{N}$-deprived or the medium contained little $\mathrm{NH}_{4}^{+}$. Capture occurred most rapidly when the prey were present at densities exceeding $20 \times 10^{3} \mathrm{ml}^{-1}$, as shown in the difference between the ingestion rates of Oxyrrhis in Expt IV. Although this value appears to be a high cell density for natural waters it is probably not unrealistic for rock pools from which Oxyrrhis was isolated. It is also likely that $\mathrm{N}$-deplete Dunaliella are captured more rapidly from low cell densities than $\mathrm{N}$ replete prey; this is the impression gained from observations during Expts I and II.

There are 2 main factors to consider in attempting an explanation of these observations. Dunaliella is a motile organism and may move towards a source of nutrients such as $\mathrm{NH}_{4}^{+}$, thus $\mathrm{N}$-deprived cells in a low nutrient environment may be attracted towards, or remain in the vicinity of, organisms releasing $\mathrm{NH}_{4}^{+}$. Microalgae can release FAA wizich may be detected by predators and hence be of assistance in prey location (Sibbald et al. 1987, Gill \& Poulet 1988). Sibbald et al. (1988) argue that a sensory mechanism is essential if prey numbers are low. Oxyrrhis was shown to be capable of taking up several amino acids; some of these appear to be rarely released by microalgae (such as MET and GLN) but others such as ALA and GLY are more common. Dunaliella is not the natural food for Oxyrrhis so a comparison of FAA release by Dunaliella with FAA uptake by Oxyrrhis is not very meaningful in evolutionary terms. Spero (1985) reports that GLY, TAU, SER, ALA and THR are attractants for the dinoflagellate Gymnodinium fungiforms but that the chemosensory response in Oxyrrhis differs depending on the food source. An initial test of chemotaxis in Oxyrrhis did suggest attraction towards FAA, but further work is required.

Sibbald et al. (1987) suggest that the attraction of microflagellates towards $\mathrm{NH}_{4}^{+}$would help individuals to locate aggregates of others feeding and hence regenerating $\mathrm{NH}_{4}^{+}$. However, if the major process of prey digestion leading to regeneration does not occur until the prey are eliminated (especially likely in a $\mathrm{N}$-deplete environment where the prey may instantaneously remove regenerated nutrients), the attraction of the individual to a prey-deplete volume of water may be of particular disadvantage as Oxyrrhis can devour smaller Oxyrrhis (Dodge \& Crawford 1974, Öpik \& Flynn unpubl.).

\section{Changes in levels of extracellular amino acids}

Dunaliella was chosen as the prey specifically because it appeared from the work of Turner (1979) to be
Fig. 5. Expt III. Uptake of FAA by preydeplete Oxyrrhis $\left(2.5 \times 10^{3} \mathrm{ml}^{-1}\right)$. (a) Disappearance of individual amino acids from the medium; initial concentration of $200 \mathrm{nM}$ plus that present in the growth medium. Uptake of LEU was almost identical to that for ILE (not shown). (b) Changes in IAA during uptake of $\mathrm{FAA}_{;}-0 \mathrm{~h}$ values are before addition of FAA to medium
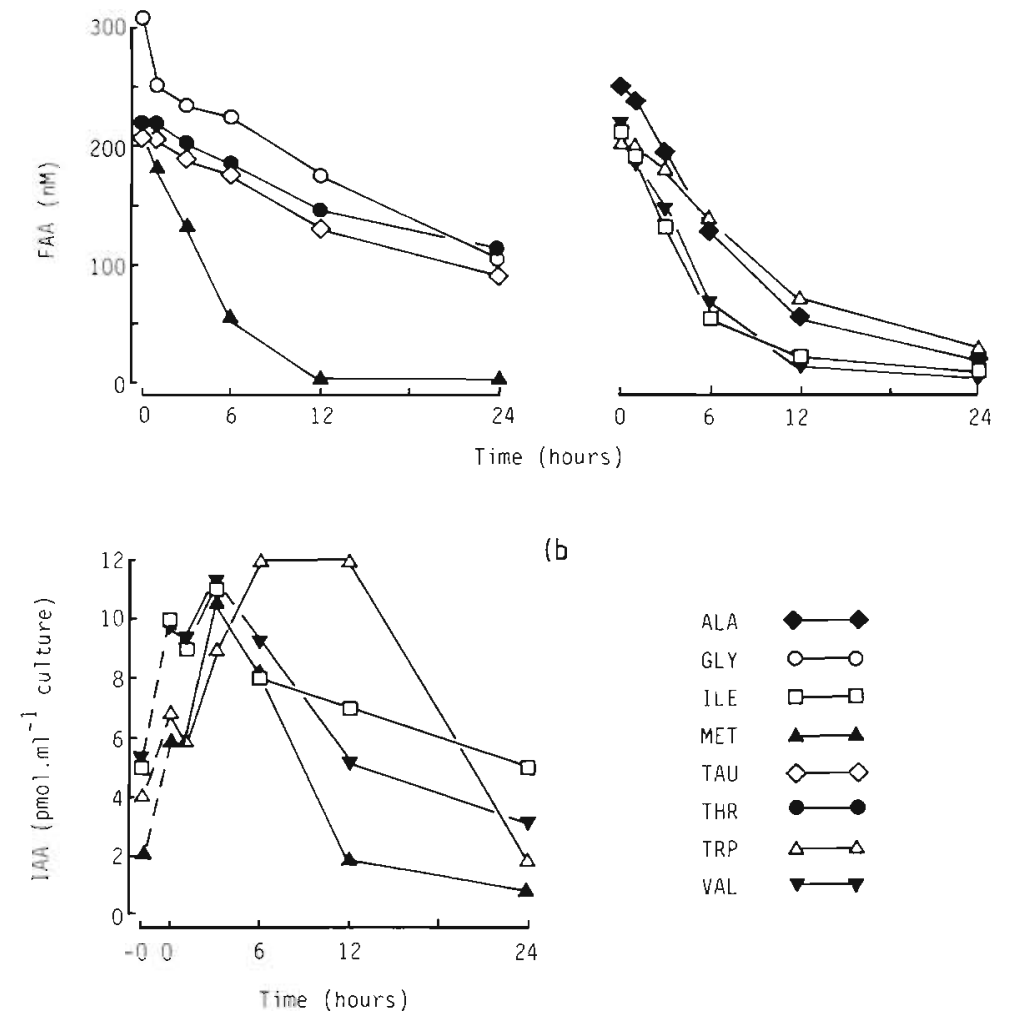

lb

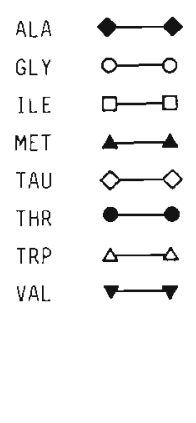


incapable of utilizing many FAA. Our experiment, in which the alga was incubated for $24 \mathrm{~h}$ in the presence of a range of FAA at a concentration of $200 \mathrm{n}$ Meach, showed no significant uptake of FAA. It is therefore most likely that levels of FAA in the media of the predator-prey experiments reflected release of FAA by the 2 organisms and uptake by Oxyrrhis. The composition of FAA showed marked changes during several of the experiments with concentrations of some FAA changing very little and others increasing several-fold. Only the major FAA are shown in the figures, most of the others were present at below $10 \mathrm{nM}$; notably these were also those for which uptake was demonstrated (Figs. 4 and 5).

The general composition of FAA release by Dunaliella is shown in Fig. 3 with the major a mino acids being GLU,
SER, THR, ALA and LEU, of which THR, ALA and LEU can be taken up by Oxyrrhis (Fig. 5a). However, in Expt IIb (Fig. 4) GLU was also taken up so it is possible that uptake of FAA also depends on the nutrient status of the Oxyrrhis. For Expt III the Oxyrrhis had been preydepleted for much longer than for Expt II whilst GLU was the major IAA in samples from the former experiment perhaps inhibiting uptake of that amino acid by transinhibition (see Flynn \& Butler 1986). If FAA uptake is associated with chemosensing then uptake may also differ with nutrient status and food source. Fitt (1985) suggests that chemosensory behaviour is suppressed when that chemical is present in the medium at relatively high concentrations or if present within the organism.

Uptake of amino-N by Oxyrrhis could provide a
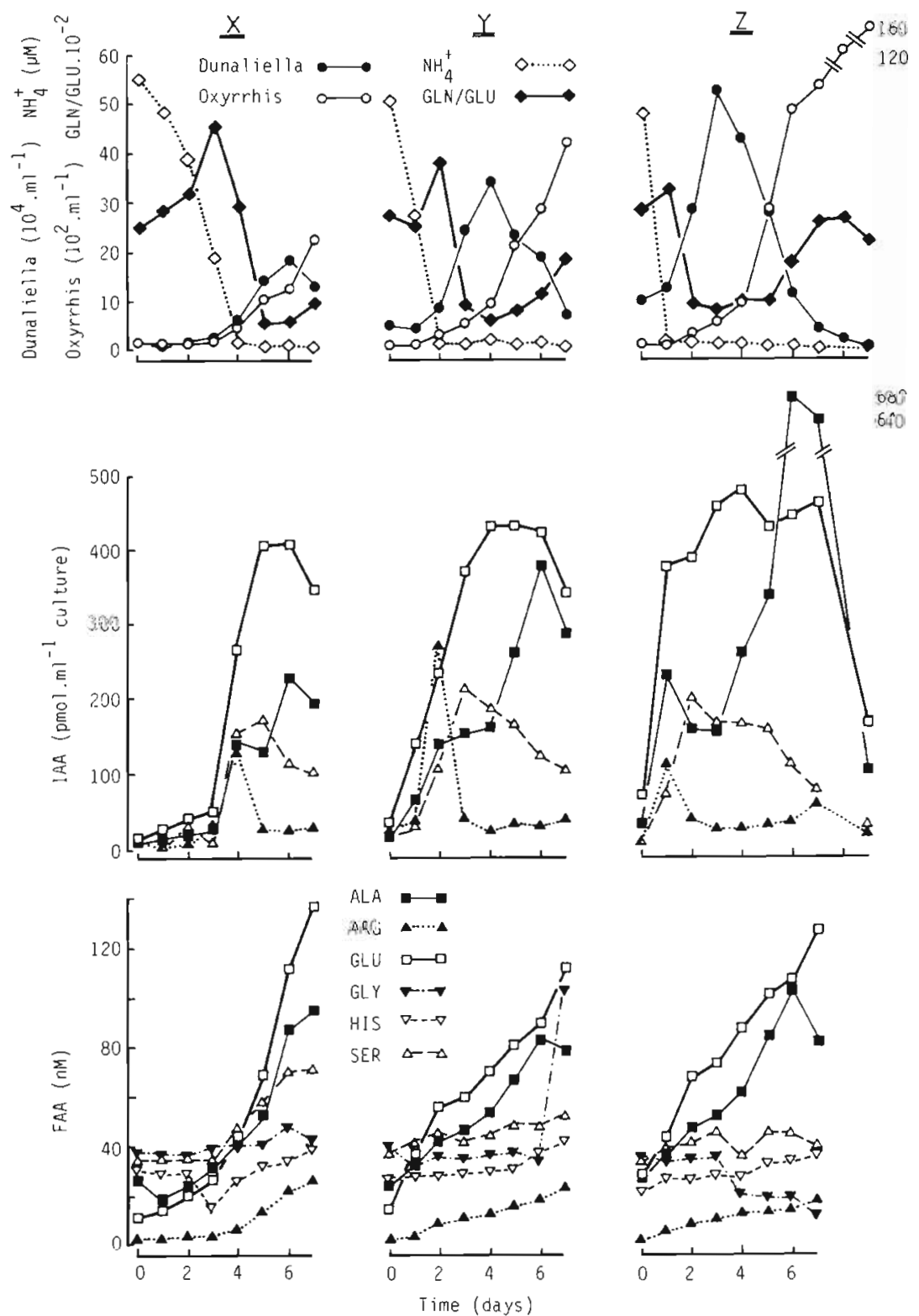

Fig. 6. Expt IV Changes in cell number, $\mathrm{NH}_{4}^{+}$, GLN/GLU, IAA and FAA during growth of a mixed population of Oxyrrhis and Dunaliella starting with identical predator densities but different prey densities 
significant proportion of $\mathrm{N}$-demand. Fifty $\mathrm{nmol} \mathrm{NH}_{4}^{+}$ will support the growth of $5 \times 10^{5}$ Dunaliella (depending on the final $\mathrm{N}$-status) and assuming a rate of capture of 20 Dunaliella per Oxyrrhis per d, this equates to an incorporation of 2 pmol $\mathrm{N}$ Oxyrrhis ${ }^{-1} \mathrm{~d}^{-1}$. Expt II suggests that Oxyrrhis is capable of a simultaneous uptake of $8+$ amino acids from an initial concentration of $200 \mathrm{pmol} \mathrm{ml}^{-1}$ each FAA by $2.5 \times 10^{3}$ cells, equating to $0.64 \mathrm{pmol} \mathrm{N}$ Oxyrrhis $^{-1} \mathrm{~d}^{-1}$ ( $32 \%$ of algal input). However, because Oxyrrhis is a heterotroph, it also requires a source of $C$. Three of the amino acids taken up, ALA, VAL and LEU, are closely linked to pyruvate metabolism, and could rapidly enter $\mathrm{C}$ metabolism. Amino acids with low $\mathrm{C} / \mathrm{N}$, such as $\mathrm{ARG}$, would not be such good sources of C-nutrition; uptake of ARG by Oxyrrhis was not significant. The development of the ability of Oxyrrhis to take up FAA when deprived of prey parallels that in autotrophic algae when subjected to $\mathrm{C}$ and/or $\mathrm{N}$ deprivation (reviewed by Flynn \& Butler 1986).

The release of ARG, and the inability of either organism to take it up from the medium, is of interest because of the amount of $\mathrm{N}$ which it represents. The release is not simply leakage because increasing amounts of ARG were present in the FAA in Expt IV when intracellular levels were low (Fig. 6). One explanation may be that release of ARG by prey-deplete Oxyrrhis represents Nexcretion similar to that of $\mathrm{NH}_{4}^{+}$. However, ammonium release was most obvious in Expt I (Fig. 1) but there was little release of ARG.

Assimilation of FAA, in comparison with digestion of algae, would probably result in relatively higher rates of $\mathrm{NH}_{4}^{+}$-release; the $\mathrm{C} / \mathrm{N}$ ratio of algae is higher than that in amino acids. The $\mathrm{C} / \mathrm{N}$ ratio of the prey will also have an effect on $N$ regeneration by predators. In the work of Andersson et al. (1985), bacteria were used as the prey and, because the $\mathrm{C} / \mathrm{N}$ ratio of bacteria is lower than for eukaryote microalgae, release of $\mathrm{NH}_{4}^{+}$and FAA is likely to be greater but clearly the nutrient status of the predator is also important. Although the prey in $\mathrm{F}$ (Fig. 2) were not $\mathrm{N}$-deprived $\left(\mathrm{NH}_{4}^{+}\right.$was present in excess), release of FAA was no greater than in other experiments presumably because the predator did not become as prey-replete. An increase in the rate of appearance of FAA may be due to an absence of uptake in the presence of leakage or to increased leakage. Oxyrrhis which are prey-replete are likely to have large internal pools of amino acids as a result of digestion of the prey perhaps leading to more leakage, whilst not needing to develop an ability to take up FAA. However, it is possible that uptake systems for a FAA for which the organism has a particular need (say MET for example), and for those FAA used in chemosensors will always exist (although a net uptake by the population may not occur).

\section{Changes in the intracellular pool of amino acids}

Levels of IAA will reflect both the levels within the prey and those in the predator; the latter will inpart be due to the release of IAA from Dunaliella during cell lysis, from the degradation of Dunaliella protein during digestion, and from the various amination reactions associated with amino acid metabolism of Oxyrrhis.

From the results of Expt IV (Fig. 6) it is apparent that the size of the peaks of ARG, ALA and SER relative to that of GLU varied as functions of the nutrient status of the prey and/or of the predator. For example the size of the ARG peak for $\mathrm{Z}$ was less than that or $\mathrm{Y}$ probably because the Dunaliella in the former were N-deprived whilst those in $Y$ were not at that point in time. The most striking difference, however, is the increasing magnitude of the ALA peak which appears to correlate with the maximum cell densities of predator for each flask.

Levels of IAA in phytoplankton are sensitive not only to changes in current supply of $\mathrm{C}$ and $\mathrm{N}$, but also to the previous history of the cells. Thus the pool of amino acids in cells which have been growing in optimum conditions does not diminish in size as rapidly as that in cells previously grown in suboptimal conditions. This subject is discussed by Flynn \& Al-Amoudi (1988) and Flynn et al. (1989). A similar event is likely to occur in heterotrophs. As a consequence, a comparison of a prey-only culture with a mixed culture is unlikely to provide reliable information from which to compute the component IAA pools of predator and prey. Filter-fractionation of mixed cultures before IAA extraction would also be of little use in this instance as prey-deplete Oxyrrhis are little larger than Dunaliella. Because release and uptake of FAA appears to be a function of physiological status, and will therefore relate to IAA levels, the use of single-organism controls to estimate contributions of FAA would also be of uncertain value.

The results from the present work suggest that the general use of proportions of amino acids as an indicator of nutrient status in mixed populations would be of little use as marked changes in IAA occur during different stages of predator-prey interaction associated with $\mathrm{NH}_{4}^{+}$ assimilation, and with heterotrophic activities such as digestion of prey protein. This is in addition to fluctuation of IAA during changes in $\mathrm{N}$-status and illumination of the algae (Wheeler et al. 1983, Flynn \& Al-Amoudi 1988, Al-Amoudi \& Flynn 1989). Another problem is the presence of unidentified amino acids. Several unknown peaks were present in our chromatograms and, because of the non-linear response of $o$-phthalaldehyde to different amino acids, quantification is impossible. It would appear that the presentation of data as mole\% $\mathrm{N}$ may lead to errors in interpretation and that the use of ratios of amino acids relative to a key amino acid, namely GLU, may be safer. 


\section{Use of GLN/GLU to indicate nutrient status}

Flynn et al. (1988) suggest that the ratio of GLN/GLU gives an indication of the current $\mathrm{N}$-status of phytoplankton, with a ratio of 0.5 indicating that levels of intracellular $\mathrm{N}$ exceed that required for protein synthesis. We have used this method in work with 8 eukaryote microalgae, a $\mathrm{N}_{2}$-fixing cyanobacterium, a yeast and a higher plant; the results have been consistent. The rational behind the method lies in the importance of the 2 amino acids in the assimilation of intracellular $\mathrm{NH}_{4}^{+}$ (Miflin \& Lea 1976, Syrett 1981). However, the role of this pathway in a phagotrophic heterotroph may be of less importance because the flow of $\mathrm{C}$ will differ and because processes of transamination will be more important; the source of $\mathrm{N}$ is as free and combined amino acids, not as inorganic N. However, elevated GLN/GLU are indicative of prey-replete Oxyrrhis (although there appears to be an initial decrease in GLU/GLN with feeding by the predator) so the population GLN/GLU will be a function of the nutrient status of both predator and prey.

The most useful set of results for this purpose is Fig. 6. Two points are of note. The first is that over the background 'noise' of the low GLN/GLU ratio of the initially prey-deplete Oxyrrhis, there was a clear increase in GLN/GLU as Dunaliella grew in the presence of $\mathrm{NH}_{4}^{+}$before the $\mathrm{N}$-source was exhausted. For Flask X, GLN/GLU reached 0.45. It should be noticed, however, that the lower initial GLN/GLU ratios in $Y$ and $\mathrm{Z}$ were not due to the lack of $\mathrm{NH}_{4}^{+}$for the Dunaliella but to elevated levels of GLU associated with feeding by Oxyrrhis. The Oxyrrhis in X were preydeplete for the first few days because the prey density was too low for efficient capture (initial cell densities of Oxyrrhis were the same in all flasks).

The second point is that the ratio of GLN/GLU increased (having fallen on exhaustion of the $\mathrm{N}$-source) during the latter part of the experiment. The simplest explanation of this is that the Dunaliella used the $\mathrm{NH}_{4}^{+}$ regenerated by the Oxyrrhis. This $\mathrm{NH}_{4}^{+}$release does not become apparent by simply measuring the concentration in the medium (compare with Fig. 1 in which Dunaliella numbers declined to near zero and $\mathrm{NH}_{4}^{+}$did rise significantly). Two factors are likely to affect the change in GLN/GLU at this time; $\mathrm{N}$-deprived algal cells supplied with $\mathrm{NH}_{4}^{+}$may have GLN/GLU as high as 5.0 (Flynn et al. 1988). In addition, the digestion of prey by Oxyrrhis was on average past the initial stages so that the initial sudden rise of GLU, and fall in GLN/ GLU, noted after the first encounter was replaced by a general lower proportion of GLU. This is apparent on comparing Figs. 1 and 2; GLN/GLU was higher in the more prey-replete Oxyrrhis at the end of Expt I than of Expt II. Thus the increase in GLN/GLU in Flask Z (Fig.
6), for example, must have been in part due to the increasing biomass of prey-sufficient Oxyrrhis.

It is concluded that the GLN/GLU ratio does work with a mixed predator-prey culture but that, perhaps, the designation of values for the ratio given by Flynn et al. (1988) are too high for mixed population studies. A. ratio of above 0.3 to 0.4 may be more appropriate as an indicator of $\mathrm{N}$-sufficiency. Clearly some identification of the components of the population need to be made for use in natural conditions, but a ratio of $<0.1$ can still be used to indicate $\mathrm{N}$-deficiency. The use of other ratios such as ARG/GLU, ALA/GLU and SER/GLU may also be considered. High ratios (say $>0,5$ ) of any one in the presence of a low GLN/GLU may indicate that heterotrophic activity is not prey-deplete. The apparent success of the GLN/GLU ratio in indicating that Dunaliella in $\mathrm{N}$-deplete media were not $\mathrm{N}$-deplete suggests that the ratio may well be of use in determinining the $\mathrm{N}$-status of microbial loop populations, as orginally hoped (Flynn 1989).

Acknowledgements. K. J. F. thanks J. W. Leftley and M. F. Turner of the Culture Collection of Algae and Protozoa (Scottish Marine Biological Association, Oban, Scotland) and J. M. Scott (Golden Sea Produce Ltd) for their help during the initial stages of this work and also C. C. A. P. for the use of facilities at Oban. J. F. is an undergraduate student of the School of Biological Sciences, Swansea. This work was funded by the Natural Environment Research Council and by a bursary from the Tansley Trust of the New Phytologist to K. J. F.

\section{LITERATURE CITED}

Admiraal, W., Peletier, H., Laane, R. W. P. M. (1986). Nitrogen metabolism of marine planktonic diatoms; excretion, assimilation and cellular pools of free amino acids in seven species with different cell size. J. exp. mar. Biol. Ecol. 98: $241-263$

Al-Amoudi, O. A., Flynn, K. J. (1989). Effect of nitrate-N incorporation on the composition of the intracellular amino acid pool of $\mathrm{N}$-deprived Tetraselmis marina. Br. Phycol. J. 24: $53-61$

Andersson, A., Lee, C., Azam, F., Hagström, A. (1985). Release of amino acids and inorganic nutrients by heterotrophic marine microflagellates. Mar. Ecol. Prog. Ser, 23: 99-106

Dodge, J. D., Crawford, R. M., (1974). Fine structure of the dinoflagellate Oxyrrhis marina III. - Phagotrophy. Protistologica 10: 239-244

Fitt, W. K. (1985. Chemosensory responses of the symbiotic dinoflagellate Symbiodinium microadriaticum (Dinophyceae). J. Phycol. 21: 62-67

Flynn, K. J. (1988). Some practical aspects of measurements of dissolved free amino acids in natural waters and within microalgae by the use of HPLC. Chem. Ecol. 3: 269-293

Flynn, K. J. (1989). Nutrient limitation of marine microbial production: fact or artefact? Chem. Ecol. 4: 1-13

Flynn, K. J., Al-Amoudi, O. A. (1988). Effects of N-deprivation and darkness on composition of free amino acid pool and on amino acid release from the diatom Phaeodactylum tricornutum Bohlin. J. exp. mar Biol. Ecol. 119: 131-143 
Flynn, K. J., Butler, I. (1986). Nitrogen sources for the growth of marine microalgae: role of dissolved free amino acids. Mar. Ecol. Prog. Ser, 34: 281-304

Flynn, K. J., Dickson, D. M. J., Al-Amoudi, O. A. (1989). The ratio of glutamine:glutamate in microalgae: a biomarker for $\mathrm{N}$-status suitable for use at natural cell densities. J. Plankton Res. 11: 165-170

Gill, C. W., Poulet, S. A. (1988). Responses of copepods to dissolved free amino acids. Mar Ecol. Prog. Ser. 43: 269-276

Miflin, B. J., Lea, P. J. (1976). The pathway of nitrogen assimilation in plants. Phytochemistry 15: 873-885

Sibbald, M. J., Albright, L. J., Sibbald, P. R. (1987). Chemosensory responses of a heterotrophic microflagellate to bacteria and several nitrogen compounds. Mar Ecol. Prog. Ser. 36: 201-204

This article was submitted to the editor
Sibbald, M. J., Sibbald, P. R., Albright, L. J. (1988). How advantagous is sensory prey detection mechanisms to predatory microflagellates? J. Plankton Res. 10: 455-464

Spero, H. J. (1985). Chemosensory capabilities in the phagotrohic dinoflagellate Gymnodinium fungiforme. J. Phycol. 21. $181-184$

Syrett, P. J. (1981). Nitrogen metabolism of microalgae. Can. Bull. Fish. Aquat. Sch. 210: 182-210

Turner, M. F. (1979). Nutrition of some marine microalgae with special reference to vitamin requirements and utilization of nitrogen and carbon sources. J. mar. biol. Ass. U. K. 59: 535-552

Wheeler, P. A., Olson, R. J., Chisholm, S. W (1983). Effects of photocycles and periodic ammonium supply on three marine phytoplankton species II. Ammonium uptake and assimilation. J. Phycol. 19: 528-533

Manuscript first received: September 20, 1988

Revised version accepted: February 2, 1989 